\title{
Awareness of ovarian cancer risk factors, beliefs and attitudes towards screening: baseline survey of 21715 women participating in the UK Collaborative Trial of Ovarian Cancer Screening
}

\section{Fallowfield*, , A Fleissig', J Barrett ${ }^{2}$, U Menon ${ }^{3}$, I Jacobs ${ }^{3}$, J Kilkerr' and V Farewell ${ }^{2}$ on behalf of UKCTOCS Trialists ${ }^{4}$}

'CRUK Psychosocial Oncology Group, Brighton \& Sussex Medical School, University of Sussex, Falmer BNI 9QG, UK; ${ }^{2}$ MRC Biostatistics Unit, Institute of Public Health, University Forvie Site, Robinson Way, Cambridge CB2 OSR, UK; ${ }^{3}$ Gynaecological Oncology, University College London, EGA Institute for Women's Health, London WIT 7DN, UK

BACKGROUND: Women's awareness of ovarian cancer (OC) risks, their attitudes towards and beliefs about screening, together with misunderstandings or gaps in knowledge, may influence screening uptake.

METHODS: In total, 21715 post-menopausal women completed questionnaires before randomisation into the UK Collaborative Trial of Ovarian Cancer Screening.

RESULTS: In all, 42.3\% correctly identified their lifetime risk of OC; 87.1\% knew that a family history of OC increased risk, but only $26.7 \%$ appreciated the association with a family history of breast cancer. Although $38.2 \%$ acknowledged increased risk postmenopause, only $8.8 \%$ were aware that OC diagnoses are highest in women over 65 years. Few (13.7\%) recognised the association between pregnancy and reduced $\mathrm{OC}$ risk or protective effects of breastfeeding (6.2\%). There were common misconceptions; $37.2 \%$ thought that an abnormal cervical smear and $26.4 \%$ that oral contraception increased the likelihood of OC. Although $84.4 \%$ recognised that most ovarian masses are benign, 20.2\% thought having had a benign cyst increased OC risk. Most (99.4\%) believed that a high uptake of $O C$ screening would reduce mortality and (96.2\%) that screen-detected cancers would have an improved prognosis.

CONCLUSIONS: The results show a need for improved public understanding about OC risks and provide important information for GPs and health educationalists about initiatives needed for future awareness, prevention and screening programmes.

British Journal of Cancer (2010) I 03, 454-46I. doi:I0.1038/sj.bjc.6605809 www.bjcancer.com

Published online 20 July 2010

(c) 2010 Cancer Research UK

Keywords: ovarian cancer screening; attitudes; beliefs; UKCTOCS

In 2007, 4317 UK women died from ovarian cancer (OC), the fifth most common cancer in women (Cancer Research UK, 2009). Earlier diagnosis is associated with improved prognosis, yet many women present too late with advanced disease. The primary aim of the UK Collaborative Trial of Ovarian Cancer Screening (UKCTOCS) is the assessment of screening on mortality. The resource implications, acceptance, physical and psychosocial morbidity of screening are also being measured. In total, 202638 post-menopausal women from the general population aged between 50 and 74 years have been recruited to the trial (Menon et al, 2008, 2009). Women from 13 centres in England, Wales and Northern Ireland were randomised into three groups: a no intervention group control, multimodal screening (annual screening with serum CA125 followed by transvaginal ultrasound scan as a second-line test) or annual transvaginal ultrasound. At trial entry, participants were asked about their awareness of OC risk factors and views about putative benefits of screening, to identify

*Correspondence: Dr L Fallowfield; E-mail: L.J.Fallowfield@sussex.ac.uk ${ }^{4}$ See Appendix A for on behalf of UKCTOCS Trialists

Received 13 April 2010; revised 16 June 2010; accepted I8 June 2010; published online 20 July 2010 possible misunderstandings or gaps in knowledge that might influence willingness to adhere to screening. Such data are also valuable for health education initiatives.

Little is known about the awareness of the risks of OC or views about screening among women in the general population of the United Kingdom, although a survey commissioned in 2007 by an OC charity and Dr Foster Intelligence suggested that $59 \%$ of women were unaware of any risk factors associated with OC (Dr Foster, 2007). Most published research has been carried out in the United States (Andersen et al, 2002, 2004; Hensley et al, 2003; Salsman et al, 2004; Lockwood-Rayermann et al, 2009), which might not extrapolate to women in the United Kingdom. The methodological inadequacies of some studies have been described (Salsman et al, 2004). Furthermore, many reports have involved women at high familial risk of OC (Wardle, 1995; Hensley et al, 2003; Andersen et al, 2004; Tiller et al, 2005) who may well have different attitudes and beliefs to the general population. However, findings to date suggest that screening attendees may overestimate their OC risk (Andersen et al, 2002; Hensley et al, 2003) and that this may be associated with psychological morbidity (Robinson et al, 1997). Women may be unaware of links between breast cancer and OC (Andersen et al, 2004) and may misunderstand the 
purpose of screening (Brain et al, 2004). There may be confusion between cervical cancer and OC screening (Black et al, 2007; Lockwood-Rayermann et al, 2009) and a lack of understanding about the fallibility of screening tests (Tiller et al, 2005; Editorial, 2009).

In this paper, we report the knowledge and pre-randomisation beliefs of 21715 women participating in UKCTOCS regarding OC risk, perceived risk factors, their attitudes towards screening and the associations of all these with sociodemographic, psychological characteristics and medical history.

\section{MATERIALS AND METHODS}

The design of the main UKCTOCS has been described in detail (Menon et al, 2008, 2009). It has ethical approval from the multicentre regional and local ethics committees, and all participants signed a consent form. Between April 2001 and October 2005, 91.6\% (185693/202638) women provided separate written informed consent to participate in the psychosocial arm of the trial, which examined knowledge, beliefs and attitudes to OC screening, together with psychological and sexual well being. Before recruitment and questionnaire completion, participants viewed an information DVD and participated in a group discussion on the need for a randomised trial. Baseline questionnaires were completed after recruitment, but before randomisation and returned to the psychosocial study centre by mail. Owing to a variety of methodological, economic and practical constraints, most previously reported research uses cross-sectional analysis. Measurement of the psychosocial impact of trial participation (which will be reported on trial completion) necessitates a truly prospective, longitudinal study. Therefore, two types of follow-up were initiated: first, the baseline data from a random sample across all three UKCTOCS groups (two screening and one control group) were automatically entered on a database for longitudinal follow-up, and second, the baseline questionnaires from the remaining participants were stored, but only entered onto the database for longitudinal follow-up if women were recalled during the trial for repeat tests or extra screens.

\section{Sample}

This paper describes data from pre-randomisation baseline questionnaires about the attitudes and beliefs of 21715 women: 1445 randomly selected at the outset and 20270 who were recalled for further tests (Figure 1). Thus, the majority of women described in this paper were randomised to one of the two UKCTOCS screening groups: $51.5 \%$ (11 191) to the multimodal group, $44.6 \%$ (9685) to the ultrasound group and the remaining $3.9 \%$ (839) to the control group. It should be noted that all the data about risk perception, attitudes and beliefs were provided at baseline before randomisation and any recall.

\section{Study measures}

Participants completed sociodemographic and medical history details and four questionnaires: (1) one (see Appendix B) probing perceived OC risk, beliefs and attitudes about screening adapted from a questionnaire used previously on breast cancer screening (Fallowfield et al, 1990); (2) the Spielberger State/Trait Anxiety Inventory (STAI) (Spielberger et al, 1983), to measure anxiety proneness (trait anxiety); (3) the General Health Questionnaire 12 (GHQ-12) (Goldberg and Williams, 1988), a screening tool to determine general psychiatric morbidity or emotional distress in clinical settings or community studies and (4) Fallowfield's Sexual Activity Questionnaire (Atkins and Fallowfield, 2007). Highest education level achieved, personal and family history of breast cancer and OC and use of oral contraception were obtained from the main UKCTOCS dataset.

\section{Statistical analysis}

Logistic regression was used for binary outcomes and proportional odds logistic regression for ordinal outcomes. The proportional odds logistic model assumes that, for any dichotomy of the ordinal scale, all odds ratios of interest, comparing the odds of observing a 'higher' outcome between two groups, do not depend on the cut point of the dichotomy. The multiple explanatory variables included in these models were age group, education level, centre,

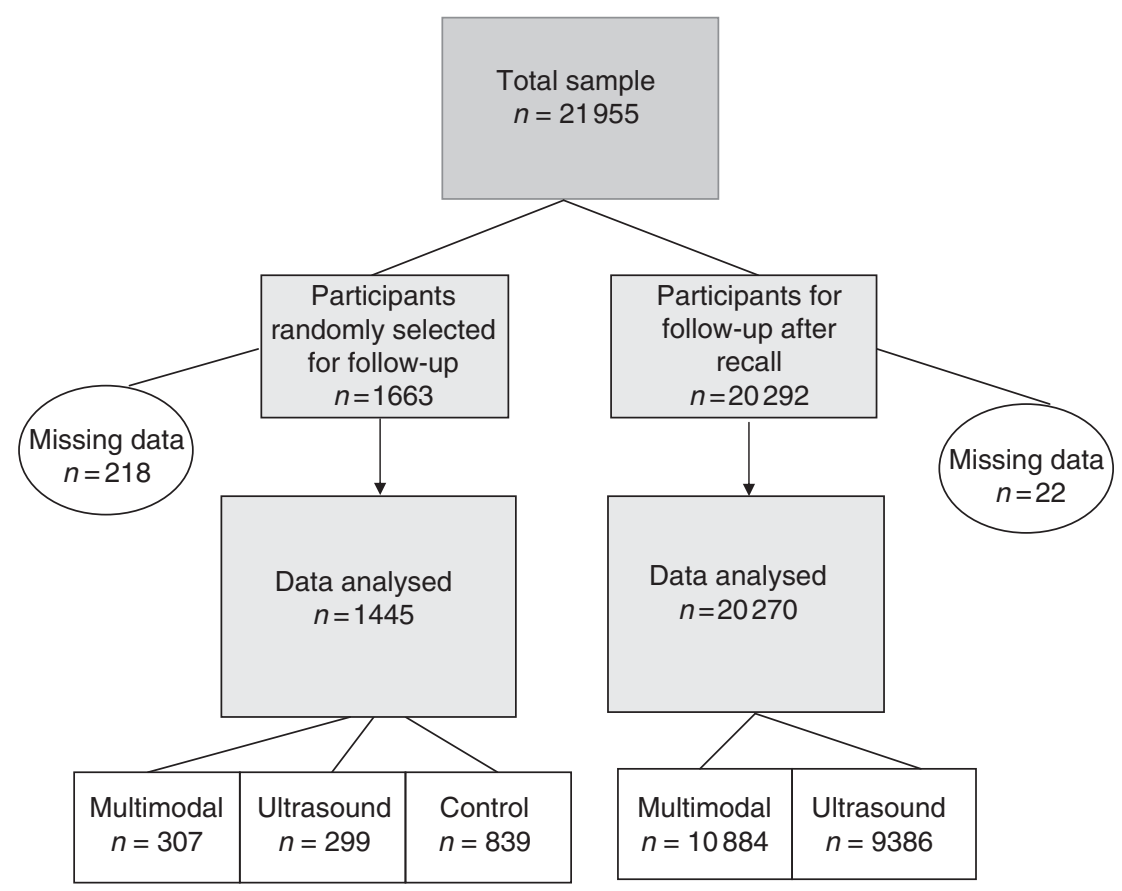

Figure I Sample description. 
anxiety level, poor psychological health, partnership status, family history of OC (at least one relative: mother, daughter, sister, grandmother, granddaughter, aunt), family history of breast cancer (at least one relative: mother, daughter, sister, grandmother, granddaughter, aunt/more than one relative: mother, daughter, sister, grandmother, granddaughter, aunt), personal history of breast cancer and having used oral contraception. Education level was categorised into three groups according to the highest formal qualifications specified: tertiary education (a university degree or a nursing/teaching qualification), secondary education (O-levels, A-levels or a clerical/commercial qualification) and no formal qualifications specified. Anxiety level was categorised in three groups: low, average and high. Low and high anxiety were, respectively, defined as an STAI trait score lower or higher than one s.d. from the mean score using the sample mean (36.5) and s.d. (10.1). The GHQ score covariate was dichotomised with a 'case' of probable psychological morbidity defined as a GHQ score of 4 or more. The results are reported as odds ratios with 95\% confidence intervals (CI). Reported results for all regression models are adjusted for centre. Analyses restricted to the random sample were undertaken, but no qualitative differences arose.

With such a large sample size, tests of the simple null hypothesis of no effect because of an explanatory variable led to many significant results. However, many of the estimated odds ratios, significant at the $5 \%$ level are close to 1 and too small to be of practical importance (Armitage et al, 2002, p. 91). Therefore, comments are restricted to those estimated odds ratios, which are over 1.5 or below 0.7 , corresponding to an increase in odds of $50 \%$, and the equivalent decrease on a log scale. The limits of 1.5 and 0.7 were chosen arbitrarily before examination of trial results. To avoid being overly restrictive, we have allowed ourselves some leeway in borderline cases and cases of earlier interest.

\section{RESULTS}

\section{Sociodemographic and psychological characteristics and medical history}

The sociodemographic and psychological characteristics of participants, which were very similar in the random- and recallbased samples and are shown in Table 1, suggest that they were representative of the general population; $50.4 \%$ reported educational qualifications (O-levels and above), which compares with $48.4 \%$ of UK females in 2005 (aged 55-64) who have attained at least upper secondary education (OECD, 2006). The mean STAI trait anxiety score of 36.5 (s.d. 10.1) is lower than that of women attending a familial OC clinic in Scotland $($ mean $=40.1$, s.d. $=9.0)$ (Cull et al, 2001), but similar to that in a UK study of women 'at risk' of developing breast cancer (Thirlaway et al, 1996). The proportion of participants (14.2\%) identified as 'cases' (GHQ-12 score $\geqslant 4$ ) is similar to the $15 \%$ of 'cases' among females (16 years or older) in England in 2003 (Prescott and Moody, 2004).

\section{Perception of risk}

When asked to estimate the lifetime risk of a woman in this country getting OC, $42.3 \%$ (95\% CI: 41.7-43.0) of the 21358 respondents gave the most accurate answer (1 in 70$)$, whereas $50.1 \%$ underestimated the risk ( 1 in 500 ) and $7.6 \%$ overestimated the risk (1 in 12). When asked to estimate their own lifetime risk of developing OC, $38.9 \%$ (95\% CI: $38.2-39.5$ ) selected 1 in $100,54.2 \%$ of 21332 selected 1 in 500 and $6.9 \%$ selected 1 in 10 . Estimation of a higher level of personal risk was associated with a personal history of breast cancer and a family history of OC and higher anxiety levels (Table 2, column 1).

Just under half of 21379 respondents believed that they were at higher risk of developing cancers other than OC $(48.3 \%$; $95 \%$
Table I Baseline characteristics of participants

\begin{tabular}{|c|c|}
\hline Age (years) & $n=21715$ \\
\hline Median (range) & $61(50-74)$ \\
\hline Mean & 60.9 \\
\hline Partnership status & $\%(n=21506)$ \\
\hline Partner & $78.4(16850)$ \\
\hline No partner & $21.6(4656)$ \\
\hline Highest educational qualification & $\%(n=20082)$ \\
\hline O-level or equivalent & $7.9(1597)$ \\
\hline A-level or equivalent & $2.3(457)$ \\
\hline Clerical or commercial qualification & | $8.4(369 \mid)$ \\
\hline Nursing or teaching & $7.0(1416)$ \\
\hline College/university degree & $14.8(2963)$ \\
\hline None specified/or stated none of the above & $49.6(9958)$ \\
\hline STAl trait anxiety $($ minimum $=20$, maximum $=80$ ) & $\%(n=21211)$ \\
\hline Low score $(20-26)$ & $16.7(3547)$ \\
\hline Average score $(27-46)$ & $66.0(13989)$ \\
\hline High score $(47-80)$ & $17.3(3675)$ \\
\hline GHQ 12 (minimum $=0$, maximum $=12$ ) & $\%(n=21598)$ \\
\hline 'Case' (score $=4$ or more) & $14.2(3077)$ \\
\hline Medical history & $\%(n=21692)$ \\
\hline At least I relative ${ }^{a}$ with ovarian cancer & $4.6(999)$ \\
\hline At least I relative ${ }^{a}$ with breast cancer & $21.9(4742)$ \\
\hline Had breast cancer & $4.0(878)$ \\
\hline Ever used oral contraception & $58.7(12735)$ \\
\hline
\end{tabular}

Abbreviations: $\mathrm{GHQ}=$ General Health Questionnaire; STAl = Spielberger State/Trait Anxiety Inventory. ${ }^{a}$ Relatives specified: mother, daughter, sister, grandmother, granddaughter, aunt.

CI: 47.6-49.0), and this was considerably more likely among respondents with a personal or family history of breast cancer and also associated with a higher level of education (Table 2, column 2).

The majority (84.4\%; 95\% CI: 83.9-84.9) of 21552 respondents were aware that most ovarian lumps turn out to be cysts rather than cancer and $13.8 \%$ did not know. Those who answered correctly were more likely to be younger, more educated and less anxious (Table 2, column 3 ).

Only 8.8\% (95\% CI: 8.4-9.2) of 21205 respondents were aware that the chances of an ovarian lump being cancer are highest in women aged over 65 years. Correct answers were mainly associated with having a family history of OC, older age and tertiary education (Table 2, column 4).

\section{Knowledge of risk factors}

Participants were given a list of factors and asked to select those they thought were associated with an increased risk of developing OC (Table 3). Most participants ( $87.1 \%)$ were aware that a family history of $\mathrm{OC}$ was associated with an increased risk of developing the disease, but only $26.7 \%$ knew of the increased risk associated with a family history of breast cancer. Less than two-fifths acknowledged the increased likelihood of developing OC after the menopause and few recognised the association between pregnancy and reduced OC risk or the protective effects of breastfeeding. A fifth associated having breast cancer with increased risk. There were also misconceptions; $37.2 \%$ associated having an abnormal cervical smear with an increased likelihood of developing OC. Over a quarter of the participants mistakenly believed that taking the contraceptive pill increases the risk, and a fifth believed a benign cyst increased the risk.

Younger participants, those with a higher level of education and those with more than one relative with breast cancer had a better awareness of these risk factors (Table 4). For younger participants 
Table 2 Relationship between responses to questions regarding perception of risk ${ }^{\mathrm{a}}$ and participants' characteristics

Odds ratio $(95 \% \mathrm{Cl})$

\begin{tabular}{|c|c|c|c|c|}
\hline Covariate & $\begin{array}{l}\text { Personal risk higher } \\
\quad(n=19082)\end{array}$ & $\begin{array}{l}\text { Higher risk of other cancers } \\
\qquad(n=19 \mid 12)\end{array}$ & $\begin{array}{l}\text { Ovarian lumps } \\
(n=1926 I)\end{array}$ & $\begin{array}{c}\text { Cancer risk by age } \\
(n=18965)\end{array}$ \\
\hline \multicolumn{5}{|l|}{ Age group } \\
\hline $60-64$ & $0.95(0.87-1.04)$ & $1.00(0.91-1.09)$ & $0.79(0.69-0.90)$ & $1.42(1.20-1.69)$ \\
\hline $65-69$ & $0.92(0.84-1.01)$ & $0.98(0.89-1.08)$ & $0.67(0.58-0.76)$ & $2.37(1.99-2.81)$ \\
\hline $70-74$ & $0.84(0.75-0.94)$ & $0.94(0.83-1.06)$ & $0.47(0.4 I-0.55)$ & $2.37(1.94-2.89)$ \\
\hline None specified & Reference & & & \\
\hline Secondary & $0.80(0.75-0.86)$ & $1.12(1.05-1.20)$ & $1.50(1.36-1.65)$ & $1.02(0.90-1.16)$ \\
\hline Tertiary & $0.74(0.69-0.80)$ & $1.55(1.44-1.68)$ & $1.98(1.76-2.22)$ & $1.74(1.54-1.96)$ \\
\hline \multicolumn{5}{|l|}{ Anxiety (STAl trait score) } \\
\hline Low & Reference & & & \\
\hline Average & $1.27(1.17-1.38)$ & $1.19(1.09-1.28)$ & $0.88(0.78-0.99)$ & $0.96(0.84-1.09)$ \\
\hline $\begin{array}{l}\text { One relative with breast } \\
\text { cancer }\end{array}$ & $1.17(1.09-1.26)$ & $1.66(1.54-1.79)$ & $1.07(0.97-1.20)$ & $1.07(0.94-1.21)$ \\
\hline $\begin{array}{l}>\text { I relative with breast } \\
\text { cancer }\end{array}$ & $1.41(1.22-1.63)$ & $3.13(2.65-3.70)$ & $1.04(0.84-1.29)$ & $0.96(0.73-1.25)$ \\
\hline Had breast cancer & $2.40(2.09-2.77)$ & $2.54(2.16-2.99)$ & $1.27(1.02-1.59)$ & $0.97(0.75-1.25)$ \\
\hline Ever used oral contraception & $0.88(0.83-0.94)$ & $1.05(0.98-1.12)$ & $1.23(1.13-1.35)$ & $1.11(0.99-1.24)$ \\
\hline
\end{tabular}

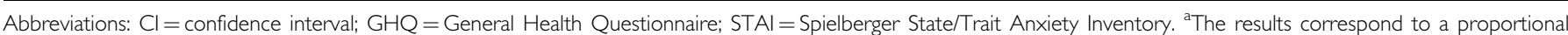
odds logistic regression of the probability of estimating a higher level of personal risk and logistic regressions for the probability of answering 'yes' to the question 'Do you think you are at higher risk of developing other cancers than ovarian cancer' and the probabilities of being aware that most ovarian lumps turn out to be cysts and that the chances of an ovarian lump being cancer are highest in women aged over 65 years, respectively.

Table 3 Women's knowledge of risk factors ${ }^{a}$

\section{\% Responding yes $(95 \% \mathrm{Cl})$}
(a) Has relatives with ovarian cancer
(b) Past menopause
(c) Has relatives with breast cancer
(d) Never pregnant
(e) Did not breastfeed
(f) Has had breast cancer
(g) Has had abnormal smear
(h) Took the pill
(i) Has had benign ovarian cyst

$87.1(86.7-87.6)$

Abbreviation: $\mathrm{Cl}=$ confidence interval. ${ }^{\text {Th }}$ The questionnaire stated 'A woman is more likely to develop ovarian cancer if she: (tick any of these you think may apply).' The sample size is 21377 . (a-e) are accepted risk factors, (f) is equivocal in the absence of family history and $(g-i)$ are not risk factors.

and those with a higher level of education, this was mainly due to their greater awareness of the risk of familial OC and the increase in risk post-menopause. Those with a higher level of education also had greater awareness of the protective effects of pregnancy and breastfeeding. The significant odds ratio for those with relatives with breast cancer was primarily due to a greater awareness of the risks associated with having family members with breast cancer and having had breast cancer.

\section{Views on susceptibility and screening}

A quarter of 21577 respondents (25.2\%; 95\% CI: 24.6-25.7) had spoken to other members of their family about the risk of OC and

this was more likely among those with a family history of OC than those without a family history (odds ratio: 2.76 ; $95 \%$ CI: $2.41-3.16)$. Participants were asked what they perceived to be the costs and benefits of screening and for their views on their susceptibility to OC (Table 5). The majority (99.4\%) believed a high uptake of OC screening would reduce mortality and (96.2\%) that screen-detected cancers would have an improved prognosis. Witnessing friends or hearing of public figures getting OC increased awareness of personal risk about developing OC for $84.8 \%$. Only $15.2 \%$ said that coming for screening would cause them to worry unnecessarily, but over two-thirds expressed concerns about developing OC.

\section{DISCUSSION}

\section{Principal findings}

Just over two-fifths of the UKCTOCS participants had an accurate awareness of lifetime population risk of OC, but half underestimated the risk. As far as personal risk was concerned, higher levels of anxiety, a personal history of breast cancer or a family history of $\mathrm{OC}$ were associated with a higher estimation.

With the exception of a family history of OC, there was a lack of awareness regarding specific risk factors and there were some common misconceptions. Only $26.7 \%$ knew of the increased risk of OC associated with a family history of breast cancer. Only $38.2 \%$ identified the increased likelihood of developing OC after the menopause (this despite participating in a trial where menopausal status was one of the eligibility criteria for OC screening) and $<1$ in 10 were aware that the chances of an ovarian mass being 
cancer are highest in women older than 65 years. Few recognised the association between lower parity and increased OC risk or the protective effects of breastfeeding. Even more importantly, there were mistaken beliefs; over a third associated having an abnormal cervical smear with an increased likelihood of developing OC and over a quarter of the participants believed taking the contraceptive pill increases the risk of OC.

Despite the absence of data yet showing conclusive benefit of OC screening, most participants believed that a high uptake of it would reduce mortality and that screen-detected cancers would have an improved prognosis. The recent campaigns and publicity to improve awareness about the symptoms of OC are clearly

Table 4 Relationship between the number of correct responses regarding risk factors ${ }^{a}$ and participants' characteristics

Odds ratio $(95 \% \mathrm{Cl})$

Covariate

Number of correct risk factor responses

Age group

$50-54$

$55-59$

$60-64$

$65-69$

$70-74$

$1.04(0.97-1.13)$

$0.92(0.85-1.00)$

$0.80(0.74-0.87)$

$0.70(0.63-0.77)$

Education level

None specified

Secondary

Tertiary

Reference

$1.32(1.24-1.40)$

$2.11(1.97-2.25)$

Anxiety (STAl trait score)

Low

Average

Reference

$0.97(0.91-1.04)$

High

$0.82(0.74-0.90)$

GHQ case (vs non-case)

Partner (vs no partner)

Relative with ovarian cancer

One relative with breast cancer

$>$ I relative with breast cancer

Had breast cancer

$0.82(0.76-0.89)$

$1.02(0.96-1.08)$

$1.15(1.02-1.29)$

$1.28(1.20-1.37)$

$1.47(1.29-1.68)$

$1.04(0.91-1.19)$

$1.08(1.02-1.15)$

Abbreviations: $\mathrm{Cl}=$ confidence interval; $\mathrm{GHQ}=$ General Health Questionnaire;

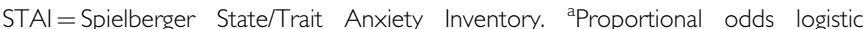
regression of the number of correct responses regarding risk factors (listed in Table 3). Definition of correct responses: items ( $a-f)$ endorsed, items ( $g-i)$ not endorsed. If no items were endorsed, $(g-i)$ non-endorsements were excluded and data treated as missing. Regression also adjusted for centre. Sample size $=19127$. important as only $41.1 \%$ recognised that it might be possible to identify symptoms sooner than waiting for screening.

Ultrasonography is an invasive procedure and more than half (51.9\%) of the participants felt that gynaecological examinations were embarrassing, which might ultimately have an effect on willingness to attend and acceptability of this form of screening. Although approximately two-thirds were concerned about getting OC, it was encouraging that few $(15.2 \%)$ said that coming for OC screening would cause them to worry unnecessarily.

\section{Strengths and weaknesses of the study}

The women participating in UKCTOCS were volunteers from the 1.2 million invited and their risk perceptions may reflect this bias. Participants' general knowledge of OC may also have been raised due to pre-recruitment information. In addition, volunteers for prevention or screening trials tend to be healthier and may be better educated and of higher socioeconomic status than the general population (Pavlik et al, 2000; Pinsky et al, 2007). Nevertheless, the formal education qualifications and GHQ scores of the UKCTOCS participants suggest that these volunteers are fairly representative of the general population and anxiety levels were not especially high. This may reflect the methods used in UKCTOCS: recruitment by random invitation using participating local authorities' registers to select participants who are more representative of the general population than those who self-refer through advertisements (Menon et al, 2008, 2009). Therefore, the knowledge about OC and attitudes of this large group of UK women, who were not at high familial risk of the disease, is valuable for estimating awareness and misconceptions among the general population.

When considering screening participation women need to consider their own risk of developing OC, as there are potential costs as well as benefits. The questionnaire asked about numeric estimates of lifetime risk, but the interpretation of probability information, is difficult (Woloshin and Schwartz, 1999; Lipkus, 2007) and it may be unnecessary for women to be able to quote numeric lifetime risk, as long as they understand the likelihood of developing OC compared with other diseases. Other methods may elicit different estimates.

The risk factors included in the UKCTOCS questionnaire were selected $>10$ years ago and other risk factors for OC have since been described including obesity, current use of hormone replacement therapy, infertility, perineal talc use and endometriosis. Recent campaigns to increase OC awareness may also have increased public understanding.

\section{Interpretation}

The results from UKCTOCS and other international studies regarding the ability of screening to detect $\mathrm{OC}$ in time to provide

Table 5 Attitudes to and beliefs about ovarian cancer and screening

N Agree (strongly/a little) ${ }^{a}(\%) \quad 95 \% \mathrm{Cl}$

Views about ovarian cancer screening

If more women went for ovarian screening, there would be fewer deaths from ovarian cancer $\quad 21586$

21590

21526

I find gynaecological examination an embarrassment

If I look out for the symptoms of ovarian cancer, I might find something sooner than if I go for screening

If a lump is found in your ovaries, it is usually too late to do anything.

Coming for screening would/has only made me worry (unnecessarily) about ovarian cancer

21423

21506

21562

21522

21474

21478

21490

The older I get, the more I think about the possibility of getting ovarian cancer

There are so many things that could happen to me, it is pointless to worry about ovarian cancer

My health is too good at present even to consider thinking that I might get ovarian cancer

${ }^{a}$ Questionnaire had four choices: agree strongly, agree a little, disagree strongly, disagree a little, which were dichotomised.
$99.3-99.5$ $95.9-96.4$ $51.3-52.6$ $40.5-41.8$ $21.9-23.0$ $14.7-15.7$ 
treatment that might influence survival, the best screening method, its acceptability to patients and other costs and benefits are still awaited. If the data do support implementation, then information including the risk perceptions of individuals who agree to OC screening may be important to our understanding of factors that motivate attendance, especially as there are reported inequalities in the use of existing breast and cervical screening services (Moser et al, 2009). Previous research suggests that OC screening attendees may believe themselves to be at higher personal risk of and worry more about the disease than others (Wardle, 1995; Andersen et al, 2002). Half of the UKCTOCS participants underestimated risk. At the same time, many thought that they were susceptible: only $48 \%$ of the UKCTOCS participants believed that they were at higher risk of developing cancers other than OC, although this was a more common belief among those with a higher level of education and those with a personal or family history of breast cancer. Views about susceptibility to OC were similar to those expressed in an earlier study among women attending for breast cancer screening, as were perceptions about the costs and benefits of screening (Fallowfield et al, 1990). Fewer of the UKCTOCS participants than those in the breast cancer screening study said that coming for screening had made them worry about cancer. Nevertheless, approximately two-thirds were concerned about getting OC. This seems excessive, considering the actual likelihood of their developing the disease, but women's anxieties could be a reflection of their knowledge that survival is often poor.

As all the UKCTOCS participants had volunteered for the study, it is not surprising that most believed in the value of OC screening, but the majority of participants also believed that an increase in uptake would reduce mortality. This finding is perhaps surprising as women had received a detailed information sheet on the pros and cons of screening and had attended an information session during recruitment, when they were informed that the primary aim of UKCTOCS is to examine whether ovarian screening can reduce mortality. The belief that screen-detected cancers would have a better prognosis is perhaps more understandable given that this is the underlying premise on which OC screening is based. These beliefs highlight the importance of presenting balanced information about the limitations as well as the benefits of screening, which has been highlighted in recent controversies about breast screening (Welch, 2009). However, even if balanced information is provided, individuals may have selective recollection of this as well as preconceived ideas about screening initiatives.

\section{Implications for clinicians and policymakers}

The 6-year UKCTOCS follow-up study will be able to examine whether an underestimation of population risk leads to poorer attendance for screening. As well as improving information about OC risk and screening, more research needs to be performed on ways of assisting comprehension and understanding.

If the risk of $\mathrm{OC}$ is underestimated in the general population, campaigns should be encouraged to increase awareness. At the same time, it is important that this should be put in perspective and women should be aware that OC is only the fifth most common cancer among women in the UK accounting for $5 \%$ of all female cancers (Cancer Research UK, 2009). Specific information to remove the confusion between cervical and ovarian screening needs to be provided and the protective effects of oral contraception should be emphasised. However, health educators do have to consider the potential confusions that can easily occur, for example oral contraception is associated with higher breast cancer risk.

Although having more educational qualifications, a family history of cancer and to some extent age were associated with improved knowledge about specific aspects of OC, there was a low level of awareness in general. Thus, the findings from this large study of UK women show the urgent need for improved public education about all aspects of OC. Opportunistic discussions with women about $O C$ when being seen by their primary care physicians and information leaflets in appropriate settings may all contribute. These results provide important information for the development of awareness initiatives that might be needed for OC prevention and for screening programmes, if they are adopted.

\section{ACKNOWLEDGEMENTS}

We are very grateful to the many volunteers throughout the UK who participated in the trial. We thank all the research nurses in participating centres who administered baseline questionnaires and the many data monitors, managers and other academic staff at the CRUK Psychosocial Oncology Group for their hard work in capturing data and ensuring quality control, in particular Hazel Beveridge, Carolyn Langridge, Valerie Jenkins, Clare Coxon and Louise Parlour. We appreciate the help of UKCTOCS staff at UCL, especially Aleksandra Gentry-Maharaj and Andy Ryan, for checking demographic details from the main database and the encouragement and helpful comments on early drafts from the UKCTOCS trialists and steering committee. Three anonymous reviewers contributed significantly to the report. Support staff at the CRUK Psychosocial Oncology Group are funded by CRUK. The Psychosocial Arm of UKCTOCS is funded by the Medical Research Council and has received additional support from the Eve Appeal. LF is funded by Cancer Research UK. UM and IJ received Department of Health funding as part of 'women's health theme' of the NIHR UCLH/UCL Comprehensive Biomedical Research Centre. JB and VF were supported by MRC funding U.1052.00.009. The study was approved by the North West research ethics committee (MREC 00/8/34) and written informed consent was given by all participants.

\section{Contributors}

LF, IJ and UM were involved in the UKCTOCS psychosocial arm study design. JK was study co-ordinator. VF and JB were independent statisticians who performed all analyses. AF, LF and JB drafted the manuscript. AF, JB and JK prepared tables and figures. All authors critically reviewed the manuscript and approved the final version. LF is the guarantor.

\section{Conflict of interest}

The authors declare no conflict of interest.

\section{REFERENCES}

Andersen MR, Nelson J, Peacock S, Giedzinska A, Dresher C, Bowen D, Urban N (2004) Worry about ovarian cancer risk and use of screening by high-risk women: how you recruit affects what you find. Am J Med Genet A 129A: $130-135$

Andersen MR, Peacock S, Nelson J, Wilson S, McIntosh M, Drescher C, Urban N (2002) Worry about ovarian cancer risk and use of ovarian cancer screening by women at risk for ovarian cancer. Gynecol Oncol 85: $3-8$

Armitage P, Berry G, Matthews JNS (2002) Statistical Methods in Medical Research 4th edn, Blackwell Science Publishing: Oxford

Atkins L, Fallowfield LJ (2007) Fallowfield's Sexual Activity Questionnaire in women with without and at risk of cancer. Menopause Int 13: $103-109$ 
Black SS, Butler SL, Goldman PA, Scroggins MJ (2007) Ovarian cancer symptom index. Cancer 109: $167-169$

Brain K, Gravell C, France E, Fiander A, Gray J (2004) An exploratory qualitative study of women's perceptions of risk management options for familial ovarian cancer: implications for informed decision making. Gynecol Oncol 92: 905-913

Cancer Research UK (2009) Ovarian Cancer: Ovarian Cancer Survival Statistics Vol. 2009. Cruk: London

Cull A, Howat S, Greimel E, Waldenstrom AC, Arraras J, Kudelka A, Chauvenet L, Gould A (2001) Development of a European Organization for Research and Treatment of Cancer questionnaire module to assess the quality of life of ovarian cancer patients in clinical trials: a progress report. Eur J Cancer 37: $47-53$

Dr Foster Healthcare Consultancy (2007) Ovarian Cancer Action National Awareness Survey, 2006/07. Dr Foster Intelligence Ltd: London

Editorial (2009) The trouble with screening. Lancet 373: 1223

Fallowfield L, Rodway A, Baum M (1990) What are the psychological factors influencing attendance, non-attendance and re-attendance at a breast screening centre? J R Soc Med 83: 547-551

Goldberg D, Williams P (1988) A User's Guide to the General Health Questionnaire.: NFER-Nelson: Windsor

Hensley ML, Robson ME, Kauff ND, Korytowsky B, Castiel M, Ostroff J, Hurley K, Hann LE, Colon J, Spriggs D (2003) Pre- and postmenopausal high-risk women undergoing screening for ovarian cancer: anxiety, risk perceptions, and quality of life. Gynecol Oncol 89: 440-446

Lipkus IM (2007) Numeric, verbal, and visual formats of conveying health risks: suggested best practices and future recommendations. Med Decis Making 27: 696-713

Lockwood-Rayermann S, Donovan HS, Rambo D, Kuo CW (2009) Women's awareness of ovarian cancer risks and symptoms. Am J Nurs 109: 36 -45; quiz 46

Menon U, Gentry-Maharaj A, Hallett R, Ryan A, Burnell M, Sharma A, Lewis S, Davies S, Philpott S, Lopes A, Godfrey K, Oram D, Herod J, Williamson K, Seif MW, Scott I, Mould T, Woolas R, Murdoch J, Dobbs S, Amso NN, Leeson S, Cruickshank D, McGuire A, Campbell S, Fallowfield L, Singh N, Dawnay A, Skates SJ, Parmar M, Jacobs I (2009) Sensitivity and specificity of multimodal and ultrasound screening for ovarian cancer, and stage distribution of detected cancers: results of the prevalence screen of the UK Collaborative Trial of Ovarian Cancer Screening (UKCTOCS). Lancet Oncol 10: $327-340$

Menon U, Gentry-Maharaj A, Ryan A, Sharma A, Burnell M, Hallett R, Lewis S, Lopez A, Godfrey K, Oram D, Herod J, Williamson K, Seif M,

\section{APPENDIX A}

\section{UKCTOCS team and affiliations}

Principle investigators: Ian Jacobs $\mathrm{FRCOG}^{1}$, Usha Menon $\mathrm{MD}^{1}$, Stuart Campbell DSc (Lond) ${ }^{2}$, Lesley Fallowfield DPhil ${ }^{3}$, Steven J Skates $\mathrm{PhD}^{4}$, Mahesh Parmar $\mathrm{PhD}^{5}$, Alistair McGuire $\mathrm{PhD}^{6}$

Leads: Alberto Lopes $\mathrm{FRCOG}^{7}$, Keith Godfrey $\mathrm{FRCOG}^{7}$, David Oram $\mathrm{FRCOG}^{8}$, Jonathan Herod $\mathrm{MRCOG}^{9}$, Karin Williamson FRCOG $^{10}$, Mourad Seif $\mathrm{PhD}^{11}$, Ian Scott FRCOG ${ }^{12}$, Howard Jenkins ${ }^{12}$, Tim Mould FRCOG ${ }^{13}$, Robert Woolas $\mathrm{MD}^{14}$, John Murdoch FRCOG ${ }^{15}$, Stephen Dobbs MRCOG $^{16}$, Nazar N Amso $\mathrm{PhD}^{17}$, Simon Leeson FRCOG ${ }^{18}$, Derek Cruickshank FRCOG ${ }^{19}$

Trial steering committee: David Luesley FRCOG ${ }^{20}$, Jack Cuzick $\mathrm{PhD}^{21}$, Julietta Patnick ${ }^{22}$, KK Cheng ${ }^{23}$, Louise Bayne ${ }^{24}$, Kate Law ${ }^{25}$, Karen Finney ${ }^{26}$

Coordinating centre team: Aleksandra Gentry-Maharaj $\mathrm{PhD}^{1}$ Matthew Burnell $\mathrm{PhD}^{1}$, Andy Ryan $\mathrm{PhD}^{1}$, Jatinderpal Kalsi ${ }^{1}$, Susan Davies $^{1}$, Gwendolen Fletcher ${ }^{1}$, Sophia Apostolidou ${ }^{1}$, Robert Liston ${ }^{1}$

${ }^{1}$ Gynaecological Oncology, UCL EGA Institute for Women's Health, London W1T 7DN; ${ }^{2}$ Create Health Clinic, London W1G $6 \mathrm{AJ} ;{ }^{3}$ Cancer Research UK Sussex Psychosocial Oncology Group at Brighton \& Sussex Medical School, University of Sussex, Falmer BN1 9PX; ${ }^{4}$ Department of Medicine, Harvard Medical School, Boston, MA 02115, USA; ${ }^{5}$ Cancer Group, Medical Research Council Clinical Trials Unit, London NW1 2DA; ${ }^{6}$ Department of Social
Scott I, Mould T, Woolas R, Murdoch J, Dobbs S, Amso N, Leeson S, Cruickshank D, McGuire A, Campbell S, Fallowfield L, Skates S, Parmar M, Jacobs I (2008) Recruitment to multicentre trials - lessons from UKCTOCS: descriptive study. BMJ (Clin Res Ed) 337: a2079

Moser K, Patnick J, Beral V (2009) Inequalities in reported use of breast and cervical screening in Great Britain: analysis of cross sectional survey data. BMJ (Clin Res Ed) 338: b2025

OECD (2006) Education at a Glance 2006: OECD Indicators, Vol. 2006. OECD Publishing: Paris, France

Pavlik EJ, Johnson II TL, Depriest PD, Andrykowski MA, Kryscio RJ, Van Nagell Jr JR (2000) Continuing participation supports ultrasound screening for ovarian cancer. Ultrasound Obstet Gynecol 15: $354-364$

Pinsky PF, Miller A, Kramer BS, Church T, Reding D, Prorok P, Gelmann E, Schoen RE, Buys S, Hayes RB, Berg CD (2007) Evidence of a healthy volunteer effect in the prostate, lung, colorectal, and ovarian cancer screening trial. Am J Epidemiol 165: 874-881

Prescott A, Moody A (2004) Self-reported health and psychological wellbeing. In Health Survey for England 2003, Sproston K, Primatesta P (eds), Vol. 10. National Centre for Social Research, TSO: London

Robinson GE, Rosen BP, Bradley LN, Rockert WG, Carr ML, Cole DEC, Murphy KJ (1997) Psychological impact of screening for familial ovarian cancer: reactions to initial assessment. Gynecol Oncol 65: 197-205

Salsman JM, Pavlik E, Boerner LM, Andrykowski MA (2004) Clinical, demographic, and psychological characteristics of new, asymptomatic participants in a transvaginal ultrasound screening program for ovarian cancer. Prev Med 39: 315-322

Spielberger C, Gorsuch R, Lusherne R, Vagg P, Jacobs G (1983) Manual for the State-trait Anxiety Inventory (form Y). Consulting Psychologists Press: Palo Alto, CA

Thirlaway K, Fallowfield L, Nunnerley H, Powles T (1996) Anxiety in women 'at risk' of developing breast cancer. Br J Cancer 73: 1422-1424

Tiller K, Meiser B, Gould L, Tucker K, Dudding T, Franklin J, Friedlander M, Andrews L (2005) Knowledge of risk management strategies, and information and risk management preferences of women at increased risk for ovarian cancer. Psychooncology 14: 249-261

Wardle J (1995) Women at risk of ovarian cancer. J Natl Cancer Inst Monogr 17: $81-85$

Welch HG (2009) Overdiagnosis and mammography screening. BMJ (Clin Res Ed) 339: b1425

Woloshin S, Schwartz LM (1999) The U.S. Postal Service and cancer screening - stamps of approval? New Engl J Med 340: 884-887
Policy, London School of Economics, London WC2A 2AE; ${ }^{7}$ Northern Gynaecological Oncology Centre, Queen Elizabeth Hospital, Gateshead NE9 6SX; ${ }^{8}$ Department of Gynaecological Oncology, St Bartholomew's Hospital, London EC1A 7BE; ${ }^{9}$ Department of Gynaecology, Liverpool Women's Hospital, Liverpool L8 7SS; ${ }^{10}$ Department of Gynaecological Oncology, Nottingham City Hospital, Nottingham NG5 1PB; ${ }^{11}$ Academic Unit of Obstetrics and Gynaecology, St Mary's Hospital, Manchester M13 9WL; ${ }^{12}$ Department of Gynaecological Oncology, Derby City Hospital, Derby DE22 3NE; ${ }^{13}$ Department of Gynaecological Oncology, Royal Free Hospital, London NW3 2QG; ${ }^{14}$ Department of Gynaecological Oncology, St Mary's Hospital, Portsmouth PO3 6AD; ${ }^{15}$ Department of Gynaecological Oncology, St Michael's Hospital, Bristol BS2 8EG; ${ }^{16}$ Department of Gynaecological Oncology, Belfast City Hospital, Belfast BT9 7AB; ${ }^{17}$ Department of Obstetrics and Gynaecology, Wales College of Medicine, Cardiff University, Cardiff CF14 4XN; ${ }^{18}$ Department of Gynaecological Oncology, Llandudno Hospital, North Wales LL30 1LB; ${ }^{19}$ Department of Gynaecological Oncology, James Cook University Hospital, Middlesbrough TS4 3BW; ${ }^{20}$ Pan-Birmingham Gynaecological Cancer Centre, Birmingham B18 7QH; ${ }^{21}$ Head of Mathematics and Statistics (Cancer Research UK), Barts and The London, London EC1M 6BQ; ${ }^{22}$ Director, NHS Cancer Screening Programmes, Sheffield S10 3TH; ${ }^{23}$ Public Health, Epidemiology \& Biostatistics, Birmingham, B15 2TT; ${ }^{24}$ Ovacome, London W1A,7WJ; ${ }^{25}$ Cancer Research UK, London WC2A 3PX; ${ }^{26}$ Medical Research Council, London W1B 1AL. 


\section{APPENDIX B}

\section{Risk perceptions questionnaire}

Please read the following statements and tick those you believe to be true about ovarian cance

1. The chances of a woman getting ovarian cancer in her lifetime in this country are (please tick one)

$$
\begin{aligned}
& \text { About } 1 \text { in } 500 \\
& \text { About } 1 \text { in } 70 \\
& \text { About } 1 \text { in } 12
\end{aligned}
$$

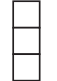

2. Most ovarian lumps turn out to be (please tick one)

$$
\begin{aligned}
& \text { Cysts } \\
& \text { Cancer } \\
& \text { Don't know }
\end{aligned}
$$

4. A woman is more likely to develop ovarian cancer if she (tick any of these you think may apply)

has never been pregnant or had children
did not breast feed
took the pill
has relatives with breast cancer
has relatives with ovarian cancer
is past the menopause
has had breast cancer
has had a benign cyst in the ovary
has had an abnormal cervical smear

5. What do you think is your lifetime risk of developing ovarian cancer?

$$
\begin{aligned}
& 1 \text { in } 10 \text { chance } \\
& 1 \text { in } 100 \text { chance } \\
& 1 \text { in } 500 \text { chance }
\end{aligned}
$$

6. Have you spoken to other members of your family about the risk of ovarian cancer?

$$
\square \text { Yes } \square \text { No }
$$

7. Do you think you are at higher risk of developing other cancers than ovarian cancer?

$$
\text { Yes } \square \text { No }
$$

8. If more women went for ovarian screening there would

strongly agree a disagree strongly agree little a little disagree be fewer deaths from ovarian cancer

9. My health is too good at present even to consider thinking that I might get ovarian cancer

10. If a lump is found in your ovaries it is usually too late to do anything about it

11. Whenever I hear of a friend/relative or public figure getting ovarian cancer I realise I could get it too

12. If I look out for the symptoms of ovarian cancer I might find something sooner than if I go for screening

13. There are so many things that could happen to me that it is pointless to think about ovarian cancer

14. Even though it is a good idea, I find gynaecological examination an embarrassment

15. The older I get the more I think about the possibility of getting ovarian cancer

16. Coming for screening would/has only made me worry (unnecessarily) about ovarian cancer

17. If I was found to have ovarian cancer by screening the chances of it being cured are highe 